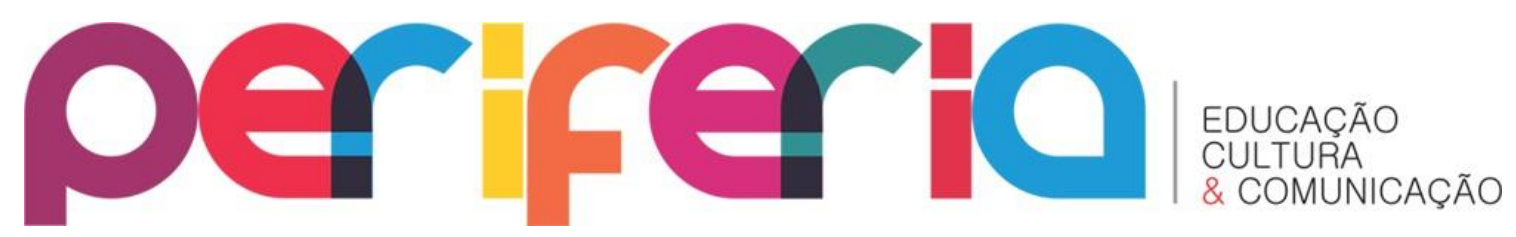

\title{
A REPRESENTAÇÃO DA MULHER À LUZ DA LEGISLAÇÃO BRASILEIRA
}

\author{
Caroline Delfino Santos 1 \\ Universidade do Grande Rio - UNIGRANRIO
}

\section{Resumo}

A subalternização da mulher em relação ao homem vem sendo alvo de contínuas reflexões e estudos. Embora as legislações vigentes apresentem avanços quanto ao direito feminino, nas relações cotidianas ainda encontramos vestígios de uma sociedade patriarcal, cuja história fundamenta-se em relações de opressão e machismo. Assim, o referido artigo apresenta como objetivo analisar processos históricos de subalternização da mulher. Para tal nos utilizaremos do método de análise documental, estabelecendo como principal fonte legislações brasileiras tendo como recorte temporal o período de 1930 até a presente data. Os resultados preliminares do presente estudo sinalizam que culturalmente as leis refletem os padrões da sociedade e corroboram para a manutenção da condição da mulher sempre subjugada e vista a partir da existência do homem. Os instrumentos normativos analisados apontam para a ratificação da hierarquia de gênero, respaldando a soberania do primeiro sobre o segundo sexo (BEAUVOIR, 2016). Concluímos que, mesmo as legislações contemporâneas a favor das mulheres, são instituídas a partir de parâmetros pautados no comportamento masculino, sendo este uma referência para todo e qualquer discurso relacionado às questões de gênero.

Palavras-chave: mulher; hierarquia de gênero; legislação Brasileira

\footnotetext{
${ }^{1}$ Mestre em Humanidades, Culturas e Artes pela UNIGRANRIO-Universidade do Grande Rio (2017). Especialista em Organização Curricular e Prática Docente na Educação Básica pela UERJ Universidade Estadual do Rio de Janeiro (2008). Graduada em Pedagogia pela UNIGRANRIOUniversidade do Grande Rio (2005). Professora e Orientadora Educacional do Ensino Fundamental na Prefeitura Municipal de Duque de Caxias, Rio de Janeiro/Brasil. carol.delfino.santos@gmail.com
}

Periferia, v. 10, n. 2, p. 239-257, jul./dez. 2018

DOI: $10.12957 /$ periferia.0.29836 


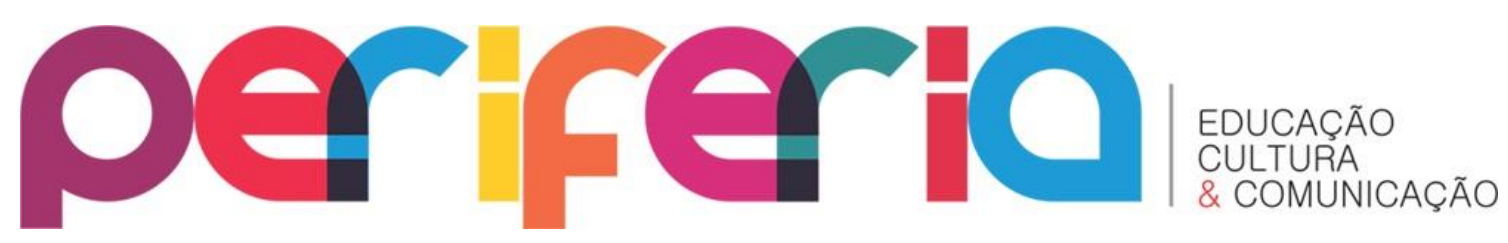

\title{
THE REPRESENTATION OF WOMEN IN THE LIGHT OF BRAZILIAN LEGISLATION
}

\begin{abstract}
The subalternization of women in relation to men has been the subject of continuous reflections and studies. Although current legislation shows advances in women's law, in everyday relations we still find vestiges of a patriarchal society whose history is based on oppression and machismo relations. Thus, the article aims to analyze historical processes of subalternization of women. For this we will use the method of documentary analysis, establishing as main source Brazilian legislation having as temporal cut the period from 1930 to the present date. The preliminary results of the present study indicate that culturally the laws reflect the standards of society and corroborate the maintenance of the condition of women always subjugated and seen from the existence of man. The normative instruments analyzed point to the ratification of the gender hierarchy, supporting the latter's sovereignty over the second sex (BEAUVOIR, 2016). We conclude that even contemporary legislation in favor of women is based on parameters based on male behavior, which is a reference for any discourse related to gender issues.
\end{abstract}

Keywords: woman; gender hierarchy; brazilian legislation 


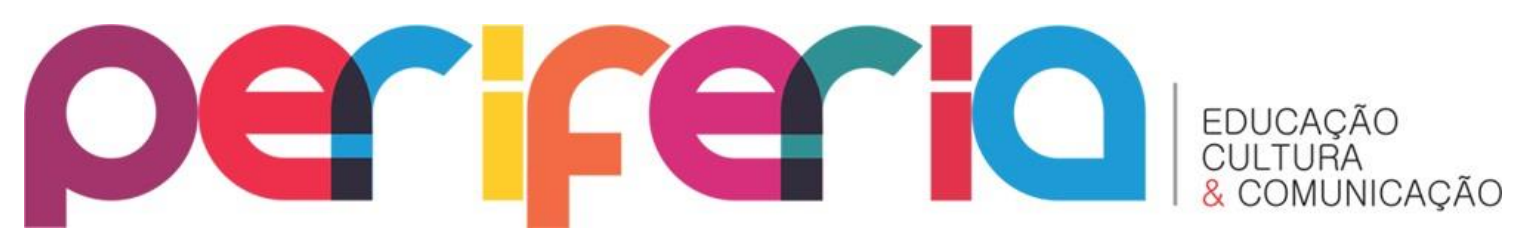

\section{INTRODUÇÃO}

As assimetrias entre o ser masculino e feminino superam as questões de ordem biológica. Os processos desiguais entre os sexos podem ser vistos em especial nos aspectos de caráter social, que vão desde a formação educacional da mulher à sua tardia e desvalorizada inserção no mercado de trabalho, em especial a mulher pobre. No campo da sexualidade, as que buscam subverter a lógica culturalmente construída de que a mulher e seu sexo existem para o prazer do masculino, recebem, mesmo nos dias atuais, rótulos e estereótipos que a diminuem frente à sociedade. Assim, o presente estudo, busca, à luz da legislação brasileira, apresentar alguns fatos que evidenciam a supremacia do sexo masculino sobre o feminino.

Em tempo, apresentaremos fragmentos da construção histórica e social do conceito de gênero, distinguindo-os da ideia de sexo. Posteriormente, nos reportaremos às legislações que se referem à condição jurídica da mulher apresentando como recorte temporal a década de 1890 até a presente data. Buscaremos traçar o perfil da mulher contemporânea a partir de sua inserção no mercado de trabalho, dentro de uma perspectiva moderna, e as diversas atribuições que assume, revelando assim uma identidade múltipla. Ao longo do texto abordaremos a educação oferecida às meninas em contraposição à oferecida aos meninos e o que o que as atuais leis preveem em casos de violação do seu corpo, a partir das mais variadas formas.

Encerraremos o presente estudo tecendo algumas considerações a respeito da construção social da mulher e a condição jurídica que lhe é imposta. As leis analisadas vão desde as que subestimam a mulher colocando à em posição inferior ao homem até as recentes leis datadas do século XXI que intentam proteger sua integridade física, moral e psicológica.

\section{CONCEITO DE GÊNERO}

Periferia, v. 10, n. 2, p. 239-257, jul./dez. 2018

DOI: 10.12957/periferia.0.29836 


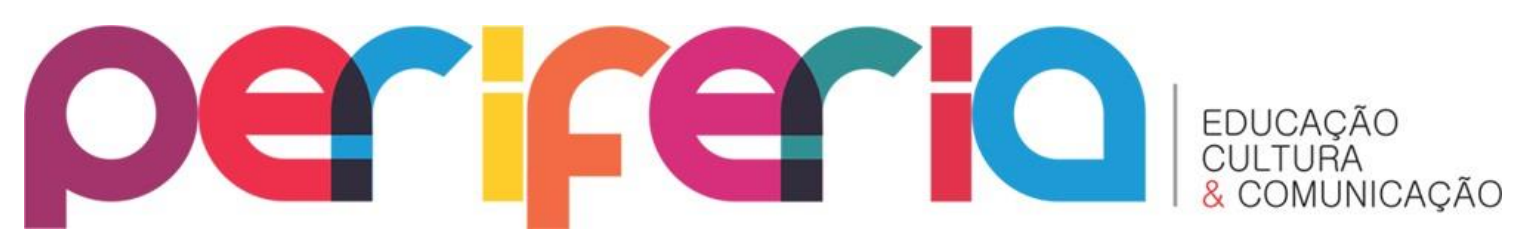

Para a construção da discussão sobre hierarquia entre os sexos, importante delinear algumas considerações em torno do conceito de gênero. Para um primeiro entendimento sobre tal conceito é preciso reconhecê-lo como uma construção social, superando a ideia de sexo restrito às questões anatômicas. Ser homem e mulher numa sociedade, não trata-se, pois, apenas de uma experiência biológica na condição de macho e fêmea. A relação de ser feminino ou masculino entrelaça-se a fatores de ordem econômica, moral, ética, judicial, social e não meramente, biológica. De igual maneira, o exercício da soberania do homem em relação à mulher, tal como poderemos observar a partir da análise das legislações, é uma construção cultural.

Em 1949, Simone de Beauvoir se debruça a escrever o livro $O$ segundo sexo. A obra reúne alguns resultados de estudos e pesquisas em torno da figura da mulher. Ao tratar das diferentes formas de opressão ao sexo feminino a autora busca não apenas questionar mas criticar os argumentos que pautavamse na biologia para limitar a mulher ao sexo. A autora também busca analisar através dos mitos, inclusive os religiosos, o papel atribuído à mulher.

Vista como a "bíblia do feminismo" O segundo sexo, à época não foi bem visto pela sociedade. Por não se tratar de um estudo enciclopédico sobre a anatomia da mulher, nem mesmo um olhar clínico-psicológico sobre o comportamento feminino, a publicação do livro, em meados do século passado, causou grandes impactos na sociedade. As críticas eram de cunho moralista, inclusive com acusações de que a obra apresenta perfil erótico, com apelo sexual. Tratava-se pois de um questionamento a respeito da soberania do macho sobre as mulheres e da sua inércia frente ao domínio masculino.

Para BEAUVOIR a identidade feminina é moldada a partir das expectativas da sociedade em torno do comportamento da menina, desde a mais tenra idade. Seu papel social é determinado pela figura do homem nos mais variados tempos históricos, desde as civilizações primitivas às sociedades contemporâneas. Como precursora de tais reflexões, a autora, por meio dos seus estudos trouxe à tona a ideia do ser social e não apenas do ser biológico incentivando as 


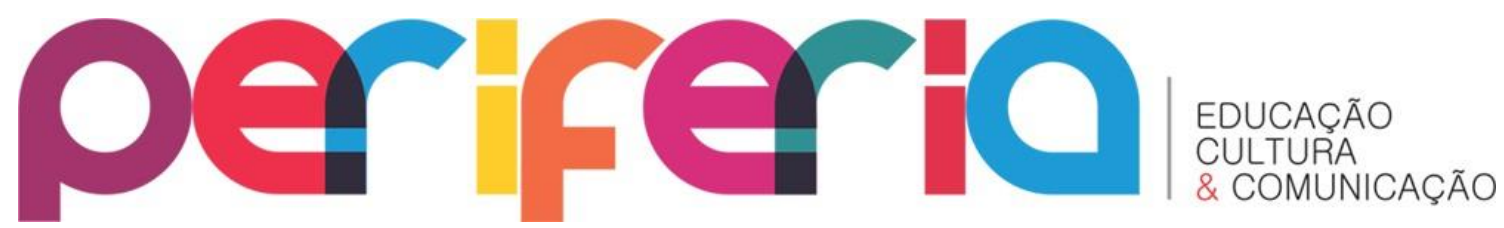

reflexões em torno de gênero com objetivo de diminuir a fronteira entre homens e mulheres.

Para melhor elucidar a origem do uso da palavra gênero, apresentamos algumas considerações de SOIHET:

Gênero tem sido desde a década de 70 , o termo usado para teorizar a questão da diferença sexual. Foi inicialmente utilizado pelas feministas americanas com vistas a acentuar o caráter fundamentalmente social das distinções baseadas no sexo. A palavra indicava uma rejeição ao determinismo biológico implícito no uso de termos como "sexo" ou diferença sexual (SOIHET, 1997, p. 101).

Gênero relaciona-se diretamente à uma construção social. Embora as assimetrias de gênero seja um dado histórico, apenas na década de 70 tal termo foi utilizado para essa discussão. Com o objetivo de distinguir os conceitos de gênero e sexo, SCOTT disserta:

O gênero é igualmente utilizado para designar as relações sociais entre os sexos. O seu uso rejeita explicitamente as explicações biológicas, como aquelas que encontram um denominador comum para várias formas de subordinação no fato de que as mulheres têm filhos e que os homens têm uma força muscular superior. 0 gênero torna aliás uma maneira de indicar as "construções sociais": a criação inteiramente social das ideias sobre os papeis próprios aos homens e às mulheres. É uma maneira de se referir às origens exclusivamente sociais das identidades subjetivas dos homens e das mulheres. 0 gênero é, segundo essa definição uma categoria social imposta sobre um corpo sexuado. Com a proliferação dos estudos do sexo e da sexualidade, o gênero se tornou uma palavra particularmente útil, porque oferece um meio de distinguir a prática sexual, dos papeis atribuídos às mulheres e aos homens (SCOTT, 1995, p.75).

Como observado, o uso da terminologia gênero pode ser empregado para dar entonação à questão relacional entre o feminino e o masculino. A supremacia de um gênero sobre o outro, nosso objeto de análise, consiste em apenas uma das hierarquias presentes em nossa sociedade dual. A demais, consideramos a hierarquia do branco sobre o negro, do ocidental sobre o oriental, dos cristãos sobre os judeus e demais denominações não cristãs. A 


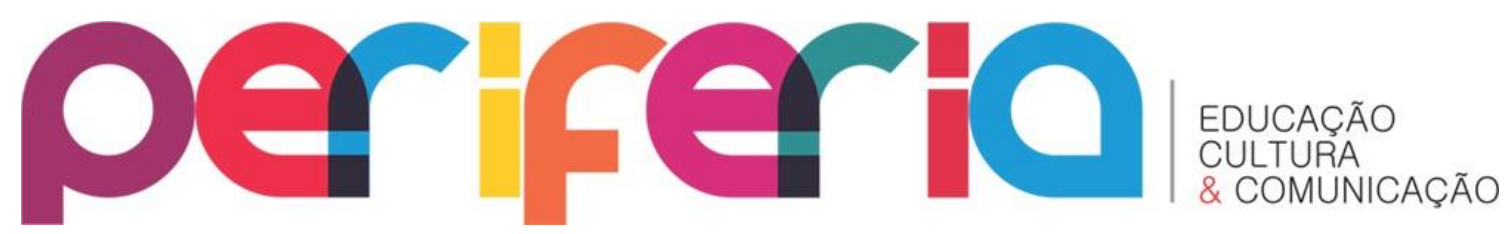

relação de soberania de uns sobre outros vem, historicamente, se revelando como cruel e opressora. A esse respeito, GALEANO reflete: "Os subordinados devem obediência eterna a seus superiores, assim como as mulheres devem obediência aos homens. Uns nascem para mandar, outros para obedecer". (GALEANO, 2005, p. 45)

A subserviência da mulher em relação aos diferentes segmentos revela aspectos de uma sociedade desigual. Esse ser tido como inferior até mesmo pela ciência sempre esteve à mercê dos comandos e diretrizes ora do pai e marido, enquanto provedores do lar, ora da sociedade, da Igreja e também do Estado.

Em decorrência das relações de gênero, a mulher pura e casta deixa a casa dos seus pais e passa a servir ao seu senhor, o marido, dando continuidade à opressão patriarcal, antes instituída. Seu corpo passa a ser propriedade do mesmo e deve estar pronto para atendê-lo. Vide decreto no 181/1890:

Art. 56. São efeitos do casamento:

$\S 1^{\circ}$ Constituir família legítima e legitimar os filhos anteriormente havidos de um dos contraentes com o outro, salvo se um destes ao tempo do nascimento, ou da concepção dos mesmos filhos, estiver casado com outra pessoa.

$\S 2^{\circ}$ Investir o marido da representação legal da família e da administração dos bens comuns, e daqueles que, por contrato antenupcial, devam ser administrados por ele.

$\S 3^{\circ}$ Investir o marido do direito de fixar o domicilio da família, de autorizar a profissão da mulher e dirigir a educação dos filhos.

$\S 4^{\circ}$ Conferir à mulher o direito de usar do nome da família do marido e gozar das suas honras e direitos, que pela legislação brasileira se possam comunicar a ela (BRASIL, 1890).

Em observância à Lei no 4.121 de 1962 que dispõe sobre a condição da mulher casada, no artigo 233 reafirma a condição do marido como líder da esposa "O marido é o chefe da sociedade conjugal, função que exerce com a colaboração da mulher, no interesse comum do casal e dos filhos" (BRASIL, 1962). Ao avançarmos na referida legislação identificamos outras normas com esse perfil. Sob as rédeas do marido a mulher se mantem até o ano de 1977, quando, por meio da lei $n^{\circ} 6.515$, é autorizado o divórcio no Brasil. A referida 


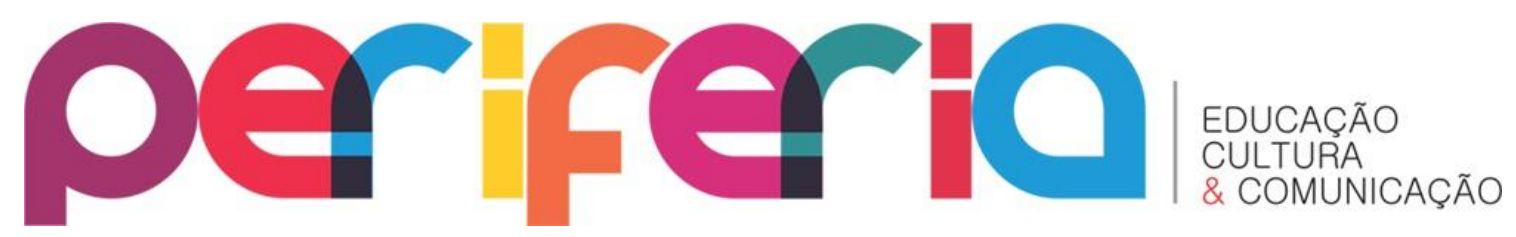

lei "regula os casos de dissolução da sociedade conjugal e do casamento, seus efeitos e respectivos processos" (BRASIL, 1977). Cumpre destacar que em razão da dependência financeira do marido, muitas mulheres acabam se submetendo a casamentos opressores, tal como analisado por BEAUVOR "O homem suserano protegerá materialmente a mulher vassala e se encarregará de lhe justificar a existência: com o risco econômico, ela esquiva o risco metafísico de uma liberdade que deve inventar seus fins sem auxílio" (BEAUVOIR, 2016, p.17). 0 julgo da sociedade contribui para que se mantenham em relações que não thes são favoráveis.

\section{A EDUCAÇÃO DA MULHER E SUA INSERÇÃO NO MERCADO DE TRABALHO: BREVES APONTAMENTOS}

Desde o período colonial, quando a educação ainda era ministrada pela Igreja, as mulheres eram excluídas desse processo de formação, cabendo apenas aos homens receber tais instruções. A educação feminina era ministrada em seu lar, com aprendizagem de atividades manuais e domésticas e assim seguiu mesmo após sua inserção na escola. Seu ingresso na escola veio acompanhado de um currículo restrito ao papel que a sociedade the impunha: dona do lar. Como se vê, um tanto quanto diferente da educação recebida pelos meninos, refletindo desde sempre as desigualdades entre os gêneros. Enquanto os homens eram preparados para honrar a nação ou os negócios, às mulheres cabia seguir fielmente um manual de conduta e boas maneiras para melhor servir ao marido.

Por meio do Decreto-Lei 21.076, de 24 de fevereiro de 1932, assinado por Getúlio Vargas, as mulheres passariam a ter direito ao voto, contudo apenas uma parte, cabendo apenas às casadas, viúvas e solteiras que apresentassem renda própria.

Em 1937, com a implementação do Plano Nacional de Educação, as meninas com idade entre 12 e 18 anos de idade, oficialmente tinha o ensino doméstico em sua grade curricular. Conforme previsto no projeto, a oferta do ensino contemplaria questões de ordem doméstica geral, preparando as 


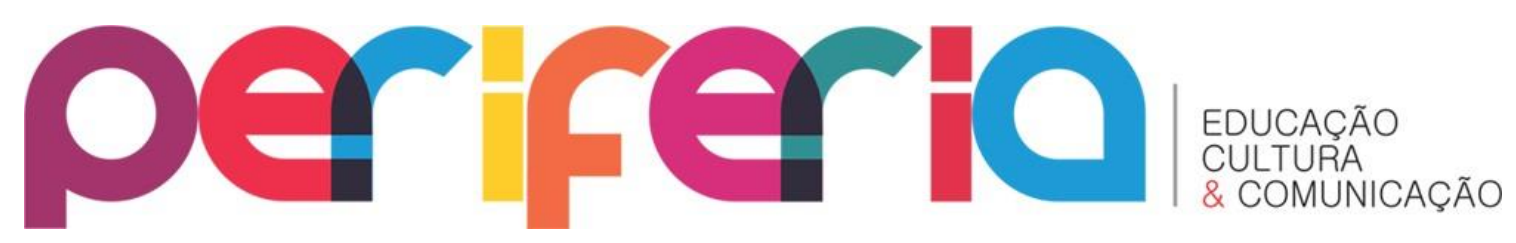

meninas para a vida no lar, teriam aulas de Português, moral familiar, noções de civilidade, matemática elementar, ginástica e canto. 0 ensino doméstico se dividiria em três categorias: do lar, agrícola e industrial. O plano foi amplamente difundido em escolas de caráter confessional, verdadeiras fábricas de donas de casa. Em 1942, o então ministro da educação e saúde Gustavo Capanema elabora o que veio a ser denominada como a Reforma Capanema, decreto-lei $n^{\circ} 4.244$. Cumpre sinalizar que o contexto histórico e político que o país vivia era o Estado Novo, um dos períodos mais autoritários vivenciados pelos brasileiros, também conhecido como a Era Vargas.

Num tempo em que Getúlio Vargas, presidente à época, se propunha a promover o desenvolvimento econômico do país, Capanema corroborava reforçando a categorização do ensino em secundário, primário e profissionalizante, vide criação do SENAI-Serviço Nacional de Aprendizagem Institucional. A divisão do ensino trazia consigo a ratificação da segregação da sociedade em classes: o ensino oferecido as elites distinguia-se do ensino oferecido às classes populares. A escola funcionaria, ainda que de forma velada, como um aparelho de estratificação social oferecendo ensino profissionalizante às massas com vistas ao desenvolvimento do país, enquanto à outra parcela da sociedade era destinado ensino voltado para o desenvolvimento do intelecto. $E$ as mulheres seguiam com uma instrução à parte: A educação feminina. Não por acaso, o plano recomendava que as meninas frequentassem escolas distintas dos meninos. Os esforços de Capanema e do governo ao qual fazia parte se concentravam em preservar a mulher no ambiente doméstico sob o discurso da conservação da família.

Quando pensamos na tardia inserção da mulher no mercado de trabalho, é importante considerarmos os grupos ais nos referimos. As mulheres das classes economicamente desfavorecidas sempre trabalharam, de forma remunerada ou não. As mulheres da classe média, até o ano de 1962 precisavam do aval do marido para o exercício da função remunerada. A partir da Lei № 4.121/1962, Estatuto da Mulher Casada a mulher passou a dispor livremente do produto do seu trabalho. 


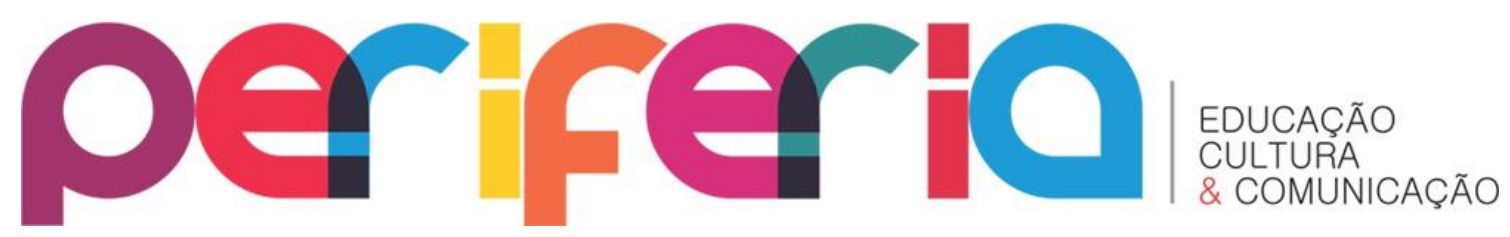

Em relação ao aceso da mulher aos serviços públicos, ainda sob a Era Vargas, por meio do Decreto-lei № 1.764/1939, artigo $3^{\circ}$ inciso VII, era estabelecido que ao elaborar projetos de lei pertinentes à proteção da família, a comissão deveria: "Assegurar aos pais de família, sem prejuízo das condições de ordem geral, a preferência para o provimento nos empregos públicos e particulares." Apenas em 1945, por meio da Carta das Nações Unidas, foi estabelecida a igualdade de direitos entre homens e mulheres.

Em meados do século XX, a igualdade de remuneração entre trabalho masculino e feminino para função igual foi aprovada pela Organização Internacional do Trabalho. Contudo no Brasil o "Salário médio de admissão está $5,29 \%$ maior, mas diferença entre homem e mulher ainda é grande. Enquanto os homens ganham $\mathrm{R} \$ 1.063,20$, em média, as mulheres recebem R\$ 917,03" (BRASIL, 2012). Tais estatística se contrapõem aos dados relacionados à escolaridade das mulheres que hoje superam aos dados apresentados pelos homens:

As Estatísticas evidenciam que, no ensino médio, houve aumento da frequência escolar feminina de 9,8\% em relação à masculina no período considerado. A taxa feminina foi de $52,2 \%$, para uma taxa masculina de $42,4 \%$. (...) Constatou-se também um contingente maior de mulheres entre os universitários de 18 a 24 anos no nível superior, em 2010. Elas representavam $57,1 \%$ do total de estudantes na faixa etária. Consequentemente, o nível educacional das mulheres é maior do que o dos homens na faixa etária dos 25 anos ou mais. Outro fator importante para a elevação do nível de escolaridade das mulheres foi a redução na proporção de adolescentes (15 a 19 anos) com filhos. Este caiu na década, de $14,8 \%$ para $11,8 \%$ (BRASIL, 2014).

Importantes dados históricos corroboraram para que muitas mulheres assumissem as rédeas dos negócios de família e intervenção na economia do país. Um deles diz respeito à Revolução Industrial e a consequente consolidação do capitalismo. O outro refere-se às I e I| Guerras Mundiais e com elas o afastamento dos homens de suas propriedades. 0 ingresso das mulheres nas fábricas e indústrias não veio acompanhada de melhorias na qualidade de vida, uma vez que as mesmas eram submetidas a péssimas condições de trabalho, 


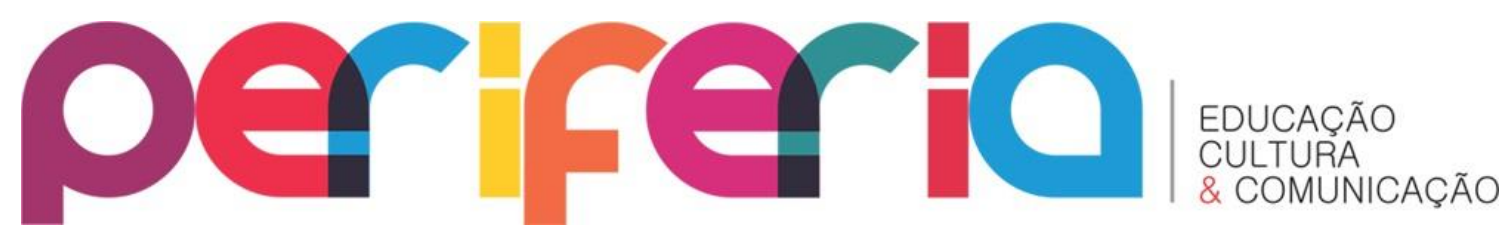

muitas horas de labor e salários distintos dos homens. A mulher passa a assumir uma dupla jornada: a de operária e dona de casa. De acordo com pesquisas realizadas pelo IPEA: “Cerca de 50\% dos homens realizam afazeres domésticos, ao passo que entre as mulheres esse percentual fica em torno de 90\%” (BRASIL, 2012).

Com o advento e liberação da pílula na década de 60, a mulher teve a oportunidade de se manter no mercado de trabalho. Com o controle da fecundidade surgiu a oportunidade de ampliar sua escolarização. Cumpre sinalizar que a o aumento da escolarização e profissionalização, ainda que técnica, era uma importante meta estabelecida a nível nacional para o desenvolvimento econômico do país. Assim, importava a ampliação do acesso de homens e mulheres à escola.

Ainda a respeito do seu papel, os movimentos em prol do processo de industrialização do país interferiram diretamente na construção social da mulher e sua identidade. Ao ter outras opções além de ser dona de casa em tempo integral, ela passa a ter autonomia para decidir se casa ou não, se tem filhos ou não, quando tê-los, com quem tê-los, quantos tê-los e como tê-los (adoção, produção independente, e mais recentemente, a coparentalidade ${ }^{2}$ ).

\section{VIOLÊNCIA CONTRA A MULHER}

A decisão sobre o próprio corpo configura-se como uma das principais bandeiras do movimento feminista, a exemplo, a luta pela legalização do aborto. A pauta de reivindicações femininas supera a luta pela igualdade de direitos entre os sexos.

\footnotetext{
${ }^{2}$ Constituição familiar sem, contudo, haver a manutenção de laços conjugais entre os pais de uma criança. Trata-se da maternidade e paternidade biológicas por meio de ato sexual, se assim as partes optarem, ou por meio inseminação artificial. Os pais têm a incumbência de prestar toda assistência à criança, conforme previsto nas legislações vigentes, assumindo a responsabilidade com a educação, saúde e bem-estar do menor. A coparentalidade ainda não é prevista nas legislações brasileiras, contudo há orientações para o tratamento dos casos como a assinatura do "contrato de geração de filhos" que pode ser feito de forma particular ou por escritura pública. Nele constará o registro da criança, a guarda compartilhada, direito de convivência, pensão alimentícia, outros. Em caso de guarda compartilhada, as orientações jurídicas que se referem aos filhos de pais separados também se aplicam à coparentalidade.
} 


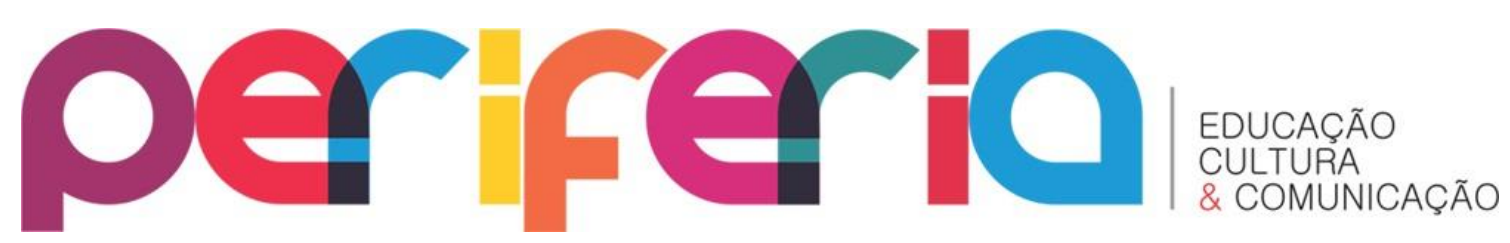

O controle sobre o corpo e o sexo da mulher, sua virgindade e honra sempre estiveram sob as rédeas e julgamento moral da sociedade, do Estado, com imposição de leis e da Igreja. Mesmo casada sua libido precisava ser contida. Seu corpo pertencia ao marido e portanto destinado ao seu bel prazer. A liberação de espasmos, gemidos, uivos ou sinais de orgasmos poderiam ser facilmente interpretados como intervenção demoníaca.

0 prazer não competia às mulheres de bem. As lésbicas são acusadas de renegarem a principal atribuição da fêmea: a reprodução, a procriação da espécie humana. A esse respeito, o grande marco da luta da mulher pelo direito de decidir a hora de gerar filhos consiste na invenção da pílula anticoncepcional. $\mathrm{O}$ advento da pílula anticoncepcional decretava que as pessoas poderiam fazer uso do sexo apenas pelo prazer e não meramente para fins reprodutivos. Embora a Igreja a condenasse, a pílula passou a ser um divisor de águas na história da liberdade sexual das mulheres.

Assim, mesmo alcançando o mercado de trabalho, a sociedade moralmente, não the autoriza a tomar as rédeas da sua própria vida, relevando os ranços de uma sociedade machista e opressora. Vide opiniões em torno da causa para o estupro, sempre atribuídas a possibilidade da mulher ter incitado o desejo masculino sobre seu corpo e sua posse sobre o mesmo.

Em consulta aos documentos legais, até o ano de 1995, o violador que casasse com a sua vítima seria isento de punição. De acordo com o exposto na Lei $\mathrm{n}^{\circ} 2848$ de 07 de dezembro de 1940, o bem estar físico e emocional da vítima não eram motivos de preocupação. De acordo com o artigo 107, a punição era extinta diante das seguintes circunstância:

VII - pelo casamento do agente com a vítima, nos crimes contra os costumes;

VIII - pelo casamento da vítima com terceiro, nos crimes referidos no inciso anterior, se cometidos sem violência real ou grave ameaça e desde que a ofendida não requeira 0 prosseguimento do inquérito policial ou da ação penal no prazo de 60 (sessenta) dias a contar da celebração (BRASIL, 1940).

Como se vê, não havia penalização pela agressão praticada contra a mulher, sua opinião se quer era consultada. 0 casamento compulsório referiaPeriferia, v. 10, n. 2, p. 239-257, jul./dez. 2018 


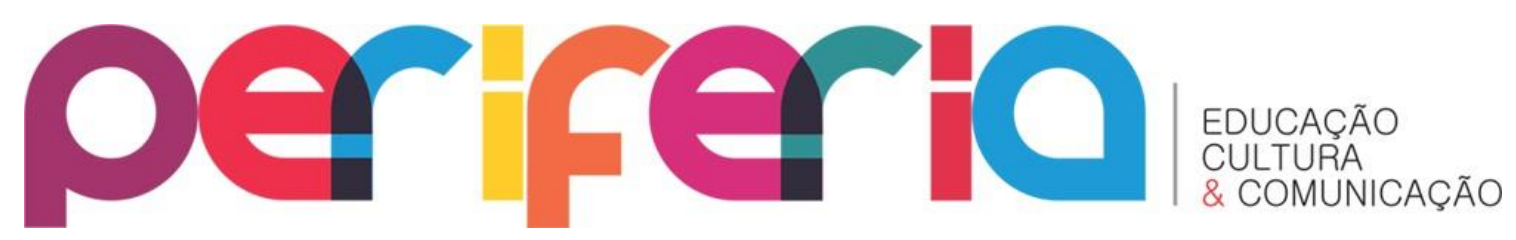

se a uma tentativa de corrigir o defloramento, sempre visando a moral e os bons costumes. Apenas em 2009, por meio da lei $\mathrm{n}^{\circ}$. 12.015 a violação do corpo, em forma de estupro ou outras formas de violência sexual contra a mulher, passou a ser vista como crime hediondo, muito em função das lutas e bandeiras defendidas pelo movimento feminista.

De acordo com o Código Penal, o estupro é considerado crime contra a dignidade sexual. A lei de $n^{\circ} 12.015 / 2009$ aponta para as seguintes mudanças em relação ao artigo 213 e outros artigos do CP:
Art. 213. Constranger alguém ${ }^{3}$, mediante violência ou grave ameaça, a ter conjunção carnal ou a praticar ou permitir que com ele se pratique outro ato libidinoso:
Pena - reclusão, de 6 (seis) a 10 (dez) anos.
$\S 10$ Se da conduta resulta lesão corporal de natureza grave ou se a vítima é menor de 18 (dezoito) ou maior de 14
(catorze) anos:
Pena - reclusão, de 8 (oito) a 12 (doze) anos.
§ 20 Se da conduta resulta morte:
Pena - reclusão, de 12 (doze) a 30 (trinta) anos (BRASIL, 2009).

Pensando na proteção à mulher, diante da incidência de casos de violência física, resultando em óbitos ou não, em 2006, é criada a Lei $n^{\circ} 11.340$, Lei Maria da Penha. Trata-se de uma legislação que cria mecanismos para coibir a violência doméstica e familiar contra a mulher. Ela visa aumentar o rigor da penalização dos crimes de ordem doméstica. A lei é aplicada nos casos de violência física e psicológica. No ano de 2012, a Organização das Nações Unidas (ONU), a intitulou como terceira melhor legislação mundial no quesito combate à violência doméstica.

A lei foi criada a partir do seguinte do histórico de tentativas seguidas de homicídios de Maria da Penha Maia Fernandes por seu então esposo. No ano de 1983, enquanto dormia, foi baleada nas costas pelo próprio marido. Como consequência Maria da Penha ficou paraplégica. Mesmo sobre uma cadeira de

\footnotetext{
${ }^{3}$ Anterior ao ano de 2009 a redação dada ao artigo 213 referia-se à mulher, tendo sido substituído por "alguém".
} 


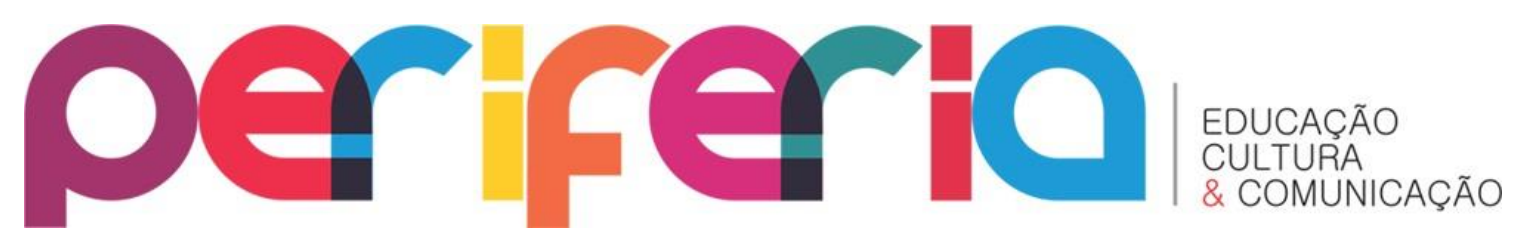

rodas, recebeu a segunda tentativa de assassinato ao ser empurrada no chuveiro. A ideia era eletrocutá-la.

Somente oito anos depois, em 1991 foi realizado o primeiro julgamento, tendo sido este anulado. A sentença viera no ano de 1996. Condenado a dez anos em estado de reclusão os advogados conseguiram recorrer. Com a ajuda da Comissão Interamericana de direitos Humanos (OEA) apenas no ano de 2002 o autor dos crimes foi preso para o cumprimento de dois anos de prisão. A organização julgou como negligente e omisso o tratamento jurídico dado ao caso, recomendando que o país criasse uma legislação específica para casos de violência doméstica, bem como a devida assistência às vítimas.

Em 2006 é criada a Lei Maria da Penha com penas mais rigorosas aos autores de crimes contra a mulher, suspendendo a prática do réu pagar multas brandas ou cestas básicas. Além da punição em casos de violência física e psicológica, também são previstos a violência patrimonial e assédio moral.

A lei prevê a proteção legal e policial às mulheres vítimas de agressão doméstica. Casos de agressão podem ser denunciados por qualquer pessoa, independente do desejo da mulher. Tal decisão pode ser vista como favorável às mulheres que mesmo sendo vítimas por anos a fio não prestam as devidas denúncias por sofrerem contínuas ameaças dos seus respectivos companheiros.

Nesse contexto, a implementação de uma Secretaria de Políticas das Mulheres configura-se como uma importante ação vinculado a planos de políticas públicas para esse grupo. Tais estratégias corroboram não apenas para a proteção de mulheres, como para a superação da assimetria de gêneros e autonomia econômica feminina.

Outra política implementada diz respeito à Central de Atendimento à Mulher, regulamentado pelo decreto $n^{\circ} 7.393 / 2010$, embora exista desde 2005. O disque 180 tem por objetivo oferecer ajuda as mulheres recebendo denúncias de violências sofridas. É uma ferramenta de proporções nacional e gratuita. Trata-se ainda de um canal de orientação dos direitos femininos, onde, a saber, são divulgadas as principais leis vigentes a favor das mulheres, instruindo-as a buscar ajudas em outras fontes disponibilizadas conforme suas respectivas demandas.

Periferia, v. 10, n. 2, p. 239-257, jul./dez. 2018

DOI: $10.12957 /$ periferia.0.29836 


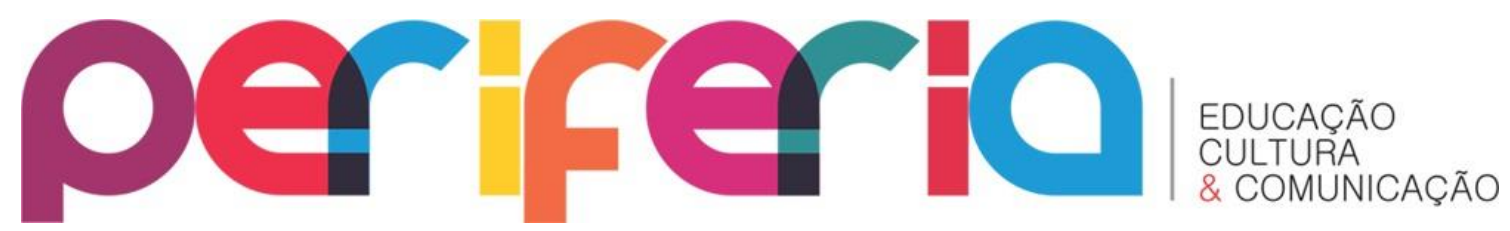

De acordo com o Relatório Anual Socioeconômico da Mulher de 2014, a Central de Atendimento à Mulher registrou os seguintes dados:

\begin{abstract}
A violência física resultou ser o tipo de violência mais frequente entre os relatos de violência registrados pela Central de Atendimento à Mulher, correspondendo a mais de $54 \%$ dos relatos computados em 2013. Os índices de violência física são seguidos por aqueles referentes à violência psicológica, representando $30 \%$ dos relatos registrados, e à violência moral, equivalente a $10,4 \%$ dos relatos. Os dados da Central de Atendimento à Mulher - Ligue 180 revelam que os agressores eram os companheiros e ex-companheiros das vítimas em mais de $69 \%$ dos relatos de violência. Embora haja o registro de violências cometidas no âmbito de relações homoafetivas, a quase totalidade dessas agressões $(99,5 \%)$ foram cometidas em um contexto de relacionamento heterossexual (BRASIL, $2015 \mathrm{~b}$, p. 38).
\end{abstract}

A central vem atuando ainda como uma importante fonte de dados para a avaliação do quadro de violência, bem como para a criação de novas estratégias de enfrentamento dessa realidade apresentada. As informações são monitoradas por unidade federal e atualizadas mensalmente.

Em observância às legislações em curso, identificamos que a Lei 10.778/2013 estabelece a notificação compulsória do caso de violência contra a mulher que for atendida em serviços de saúde, públicos ou privados, em todo o território nacional:

A notificação compulsória dos casos de violência de que trata
esta lei tem caráter sigiloso, obrigando nesse sentido as
autoridades sanitárias que a tenham recebido.
Parágrafo único. A identificação da vítima de violência referida
nesta Lei, fora do âmbito dos serviços de saúde, somente
poderá efetivar-se, em caráter excepcional, em caso de risco à
comunidade ou à vítima, a juízo da autoridade sanitária e com
conhecimento prévio da vítima ou do seu responsável (BRASIL,
2013).

Em casos da vítima buscar socorro médico, a lei $\mathrm{n}^{\circ} 12.845$, de $1^{\circ}$ de agosto de 2013 Dispõe sobre o atendimento obrigatório e integral de pessoas em situação de violência sexual: 


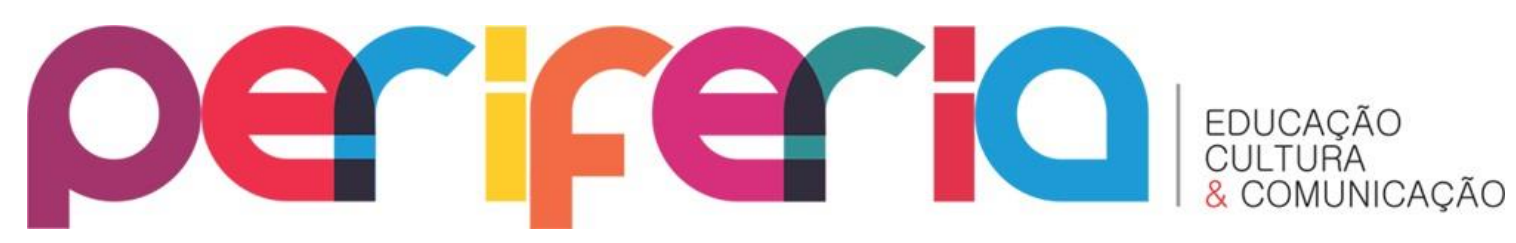

Art. $1^{\circ}$ Os hospitais devem oferecer às vítimas de violência sexual atendimento emergencial, integral e multidisciplinar, visando ao controle e ao tratamento dos agravos físicos e psíquicos decorrentes de violência sexual, e encaminhamento, se for o caso, aos serviços de assistência social.

Art. $2^{\circ}$ Considera-se violência sexual, para os efeitos desta Lei, qualquer forma de atividade sexual não consentida.

Art. $3^{\circ} \mathrm{O}$ atendimento imediato, obrigatório em todos os hospitais integrantes da rede do SUS, compreende os seguintes serviços:

I - diagnóstico e tratamento das lesões físicas no aparelho genital e nas demais áreas afetadas;

II - amparo médico, psicológico e social imediatos;

III - facilitação do registro da ocorrência e encaminhamento ao órgão de medicina legal e às delegacias especializadas com informações que possam ser úteis à identificação do agressor e à comprovação da violência sexual;

IV - profilaxia da gravidez;

V - profilaxia das Doenças Sexualmente Transmissíveis - DST;

VI - coleta de material para realização do exame de HIV para posterior acompanhamento e terapia;

VII - fornecimento de informações às vítimas sobre os direitos legais e sobre todos os serviços sanitários disponíveis (BRASIL, 2013).

Em março de 2015, por meio da Lei $\mathrm{n}^{\circ}$ 13.104, o Código Penal-Decreto Lei 2.848/1940, tem a redação do artigo 121 alterada e passa a "prever o feminicídio como circunstância qualificadora do crime de homicídio" (BRASIL, 2015), no art. $1^{\circ}$ da Lei 8.072/1990, a Lei de Crimes Hediondos passa a incluir o feminicídio ${ }^{4}$.

\section{CONSIDERAÇÕES FINAIS}

Para entendermos a representação da mulher na sociedade, nos utilizamos da análise dos documentos oficiais tendo como recorte temporal o período republicano. A inferiorização da mulher em relação ao homem é histórica e encontra respaldo legal para sua perpetuação. Por um tempo o homem intentou utilizar a biologia a seu favor. Nem mesmo a ciência foi capaz de justificar a supremacia do sexo masculino sobre o feminino.

\footnotetext{
${ }^{4}$ Homicídio de mulheres em razão de violência doméstica ou em contexto de discriminação.
}

Periferia, v. 10, n. 2, p. 239-257, jul./dez. 2018

DOI: 10.12957/periferia.0.29836 


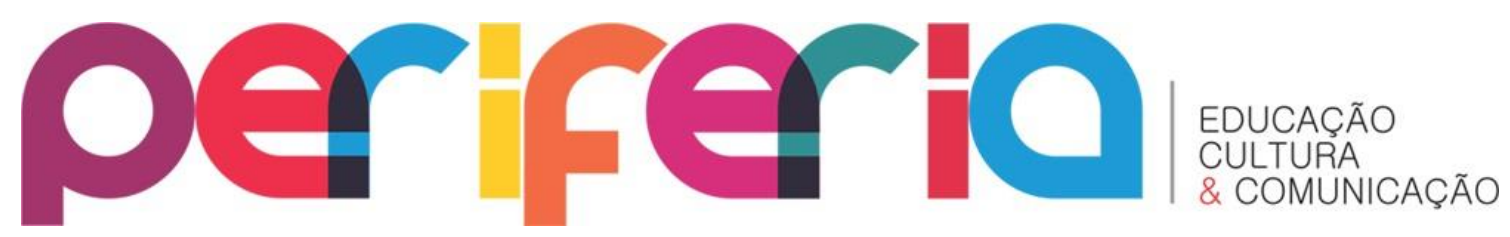

A busca por igualdade de direitos configurou-se em um longo período e mesmo hoje com o aumento de sua escolaridade e já inserida no mercado de trabalho é possível observar que há disparidades salariais para o exercício de mesmas funções. A esse respeito, disserta Beauvoir:

Economicamente, homens e mulheres constituem como que duas castas; em igualdade de condições, os primeiros têm situações mais vantajosas, salários mais altos, maiores possibilidades de êxito do que suas concorrentes recémchegadas. Ocupam na indústria, na política, etc., maior número de lugares e os postos mais importantes (BEAUVOIR, 2016, p. 17).

No quesito salário, homens também seguem à frente das mulheres. Se num dado momento histórico importava-lhe o status de ser líder em relação à mulher, atualmente buscam-se outras formas veladas ou não de manter a mulher numa posição abaixo, a exemplo, inferiorizando seus rendimentos e assim diminuindo sua capacidade de autonomia e subsistência.

A igualdade entre os sexos pode até configurar-se como um marco juridicamente, contudo conforme dados apontados ao longo do estudo, a assimetria entre os gêneros ainda é uma realidade. Como se vê, até meados do século passado a mulher era legalmente considerada incapaz, sendo gerida pelas ações e decisões do marido. A mulher se quer tinha direito a voto no Brasil.

Em análise aos recentes documentos legislativos datado desse século, observamos que algumas leis e decretos não propriamente articulam-se a favor do desenvolvimento, visibilidade e valorização da mulher, nem mesmo garantem formas mais igualitárias entre homens e mulheres. 0 que observamos é que tais legislações referem-se a mecanismos de proteção frente as práticas de violência exercidas por homens em diferentes posições e cenários: no ambiente doméstico, nas ruas, no trabalho. Tratam-se, pois, de instrumentos normativos destinados a homens, partindo sempre das suas condutas de violência para com as mulheres. Assim, o presente estudo não nega a importância dos movimentos e avanços logrados até o presente, contudo 


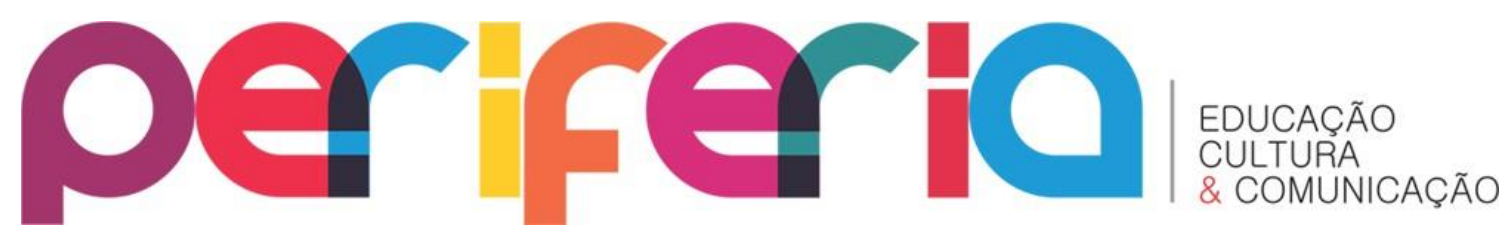

sinaliza que a representação social da mulher ainda é construída tendo a figura masculina como referência. Consideramos, pois, importante incluir a formação dos homens na pauta de política a favor das mulheres.

\section{REFERÊNCIAS}

ALTMAN. M. Hoje na História: Começa a ser vendida a primeira pílula anticoncepcional. São Paulo, 2013. Disponível em <http://operamundi.uol.com.br/conteudo/historia/28670/hoje+na+historia+1 960+\% $96+$ comeca $+a+$ ser+vendida+a+primeira+pilula+anticoncepcional+.shtml> . Acesso em 27 jun 2017

BEAUVOUIR, S. O segundo Sexo: Fatos e Mitos. $4^{\text {a }}$ Ed. São Paulo: Difusão Europeia do Livro, 2016.

BRASIL. Decreto $n^{\circ} 181$, de 24 de Janeiro de 1890. Disponível em <http://www2.camara.leg.br/legin/fed/decret/1824-1899/decreto-181-24janeiro-1890-507282-publicacaooriginal-1-pe.html >. Acesso em 13 jul 2017

. Decreto $n^{\circ} 21.076$, de 24 de fevereiro de 1932. Diário Oficial da União. Ano 1932, Página 3385, fev. 1932. Disponível em <http://www2.camara.leg.br/legin/fed/decret/1930-1939/decreto-21076-24fevereiro-1932-507583-publicacaooriginal-1-pe.html>. Acesso em 06 jul 2017

. Decreto Lei 1.764 de 10 de novembro de 1939. Câmara Legislativa Brasileira. Disponível em: <http://www2.camara.leg.br/legin/fed/declei/1930-1939/decreto-lei-176410-novembro-1939-411509-publicacaooriginal-1-pe.html>. Acesso em 20 jul 2017.

. Decreto Lei $\mathrm{n}^{\circ} 2848$ de 07 de dezembro de 1940. Diário Oficial da República Federativa do Brasil, Poder Legislativo, Brasília, D.F. Disponível em <http://www.jusbrasil.com.br/topicos/10627547/artigo-107-do-decreto-lei-n2848-de07-de-dezembro-de-1940>. Acesso em 03 jul 2017

Decreto-lei no 4.244, de 9 de abril de 1942. Lei orgânica do Ensino Secundário. Poder Legislativo, Brasília, D.F. Disponível em <http://www2.camara.leg.br/legin/fed/declei/1940-1949/decreto-lei-42449-abril-1942-414155-publicacaooriginal-1-pe.html>. Acesso em 04 jul 2017

. Lei $n^{\circ} 4.121$ - de 27 de agosto de 1962. Diário Oficial da República Federativa do Brasil de 3/9/62. Disponível em <http://www.planalto.gov.br/ccivil_03/leis/1950-1969/L4121.htm>. Acesso em 20 jun 2017 


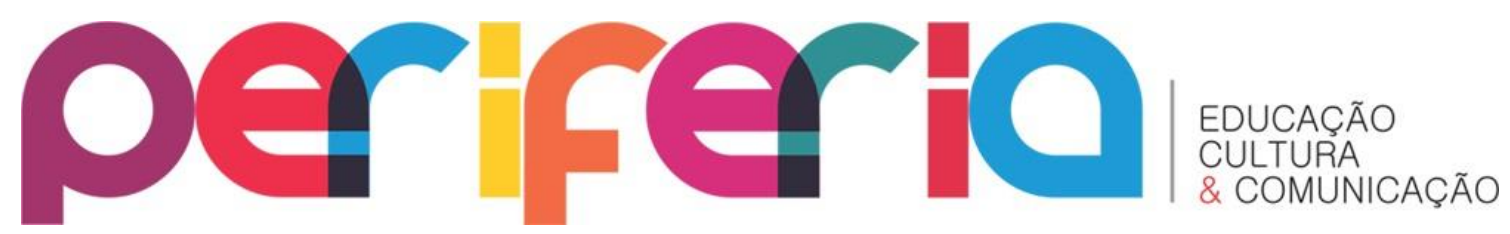

. Lei $n^{\circ}$ 6.515. Brasília, 26 de dezembro de 1977. Disponível em <http://www.planalto.gov.br/ccivil_03/leis/L6515.htm>. Acesso em 10 jun 2017

Lei $N^{\circ} 12.015$. Brasília, 7 de agosto de $2009.188^{\circ}$ da Independência e $121^{\circ}$ da República. Disponível em <http://www.planalto.gov.br/ccivil_03/_ato20072010/2009/lei/l12015.htm>. Acesso em 26 jul 2017

. Lei n $\mathrm{n}^{\circ} 13.104,09$ de março de 2015. Brasília. Disponível em <http://www.planalto.gov.br/ccivil_03/_Ato2015-2018/2015/Lei/L13104.htm>. Acesso em 29 jul 2017

- Brasil. Presidência da República. Secretaria de Políticas para as Mulheres. Relatório Anual Socioeconômico da Mulher. $1^{\text {a }}$ Impressão. Brasília: Secretaria de Políticas para as Mulheres. 2015b. Disponível em $<$ http://www.spm.gov.br/central-deconteudos/publicacoes/publicacoes/2015/livro-raseam_completo.pdf >. Acesso em 29 jul 2017

. Lei 10.778, 24 de novembro de 2013. Brasília. Disponível em <https://www.planalto.gov.br/ccivil_03/LEIS/2003/L10.778.htm>. Acesso em 29 jul 2017

DUARTE, C. L.; ASSIS, E. de; BEZERRA, P. C. (Org's.) Gênero e representação na literatura brasileira. Belo Horizonte: Pós-graduação em Letras e Estudos Literários/UFMG, 2002.

GALEANO, E. De pernas pro ar. A escola do mundo ao avesso. Porto Alegre: L\&PM,2005.

FARIA, L. Ideologia e utopia nos anos 60: Um olhar feminino. Rio de Janeiro: EdUERJ, 1997.

FOUCALT, M. A ordem do discurso. 5a edição. São Paulo: Edições Loyola, 1999. A arqueologia do saber. Rio de Janeiro: Forense Universitária, 2012.

KAWABATA, Y. A casa das belas adormecidas. São Paulo: Estação Liberdade, 2004.

NAÇÕES UNIDAS. Carta das Nações Unidas, de 26 de junho de 1945. São Francisco. Disponível em <http://www.gddc.pt/direitos-humanos/textosinternacionais-dh/tidhuniversais/onu-carta.html>. Acesso em 07 jul 2017 


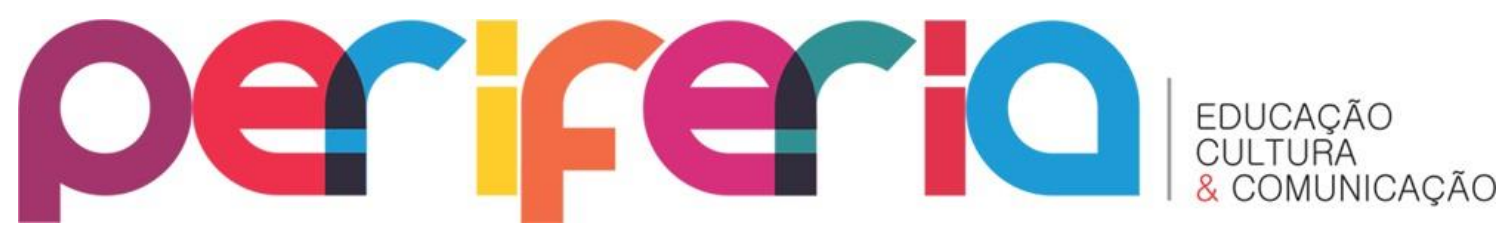

Organização Internacional do Trabalho. Igualdade de Remuneração de Homens e Mulheres Trabalhadores por Trabalho de Igual Valor. 1951. Disponível em <http://www.oitbrasil.org.br/node/445>. Acesso em 08 jul 2017

SCOTT, J. W. Gênero: Uma categoria útil de análise histórica. Educação e realidade. Porto Alegre. Vol. 20, n², pp 71-99, julho-dezembro/1995.

SOIHET, R. História, mulheres, gênero: Contribuições para um debate. In: AGUIAR, N. (org.). Gênero e Ciências Humanas: Desafio às ciências desde a perspectiva das mulheres. Rio de Janeiro: Record Rosa dos tempos, 1997. P. 95-114. 